\section{Branko Z. Popović ${ }^{1}$}

\section{HOW TO GET GOOD PRODUCTION PROCESS ?}

Abstract: In every realization of the production process certain input materials (raw materials, energy, information), management (adjustment, checking, inspection) and necessary resources (equipment, machines, computers) are included in order to obtain production results. Process results can be necessary for processed materials, finished products, management software, and useful service. The obtained results of the process go through a control process that determines: nonconformity, defect, correction, rework, repair and scrap. Usually, a good production process with a high percentage of correctness, a low percentage of corrections, and a minimum percentage of wrong process results are planned. How to get a good production process? A good production process must have a certain dependency, the necessary precision, the necessary accuracy, the desired economy, and the minimum duration. In this paper, we show how the bad process can be repaired to become a good production process.

Key words: Process production, Dependence, Precision, Accuracy, Economy, Duration.

\section{Introduction}

In every realization of the production process, certain input materials (raw materials, energy, information), management (adjustment, checking, inspection) and the necessary resources (equipment, machines, computers) are involved in order to get the output results. Process results can be: processed materials, product, hardware, software, or service. The obtained results of the process go through the following process of control which determines: nonconformity, defect, correction, rework, repair and scrap. Usually, a good production process is planned with a high percentage of correct, small percentage of repairs and a small percentage of incorrect process results. How to recognize a good production process? A good manufacturing process must meet the following requirements: defined dependence, appropriate precision, necessary accuracy, desirable economy and minimum duration. In this paper we show the ways that the poor manufacturing process can be repaired so that it becomes a good process, using the modern computer programs Minitab ${ }^{\circledR}$ and Companion by Minitab $\AA$ (Popovic, 2018).

\section{Dependence of the production process}

The production process must meet the requirement of defined dependence that determines the relationship between the

\footnotetext{
${ }^{1}$ Corresponding author: Branko Z. Popović Email: branko@popovic.org
} 
flows of the process and the actionable quantities. The defined dependency of the process is determined by Regression analysis, in Mathematics and Statistics. The elements of the regression analysis include input data, the calculation process, and the output results, from a set of functionally bound variables and their characteristics. System sizes are properties or characteristics of a phenomenon that can be variables, parameters, constants, quantitative or qualitative quantities. Quantity variables are variable measurable sizes, from a numerical scale (eg $1.2 \mathrm{~mm}$ ) with an infinite or continuous (Continual) number of values. Quality variables are variable estimable sizes, from a category scale (eg cold, warm) with a limited or discrete (Discrete) number of values.

Input data of regression analyzes are significant external impacts, which include the collected data on the causes and consequences of certain problems. Data on the causes of the problem are independent factors (Predictor variables, $x i=1,2,3, .$. ) which probably affect the observed effect of the problem. The consequence of a certain problem is the dependent variable (Response variable, y) which arises due to the action of independent factors (popovic, 2019).

The process of regression analysis involves calculating the solution of the problem, using the input data, the regression model method and using automated computer procedures and using electronic computers, to obtain the output of the regression analysis of (Taguchi, 2005; Popović, 2005) .

Output results of regression analysis are significant internal impact values that comprise calculated: regression functions, estimation of regression coefficients, analysis of calculated variation adjustments, adaptation performance estimation, calculated adaptation differences, prediction of future results, diagnostic results and specific characteristics of the model (popovic 2019).

If a regression analysis does not give a favorable performance appraisal, it must be repeated with another kind of quantitative or qualitative size, as well as independent factors and responses.

Let's look at the process of testing the effects of wear: Wear [10-4 mm3] pistons with $\mathrm{n}=4$ tubes, depending on the cause of lubrication with different viscosities of cylinder oil Oil [CP], with allowed wear tolerance $\mathrm{T}=200$ [10-4 mm3]. After testing the wear of pistons with different viscosities of the cylindrical oil, the following results were obtained, which had an average without clustering (within) 148.1 and a standard deviation 53,8:

Oil: $1.6 ; 9.4 ; 15.5 ; 20.0 ; 22.0 ; 35.5 ; 43.0$; 40.5; 33.0 [CP] i

Wear: $240 ; 181 ; 193 ; 155 ; 172 ; 110 ; 113$; $75,94\left[10^{-4} \mathrm{~mm}^{3}\right]$.

Using the quantitative linear single regression analysis, the results are shown in Figure 1 and the regression analysis diagram in Figure 2. The observed regression function, the high percentage of determinations (Rsq) and (Rsq adj) and the criterion $\mathrm{P} \leq(\alpha=0.05) \Rightarrow \mathrm{H} 1$ which confirm the validity of the regression analysis. The resulting output results completely define this wearing process, the relationship between the flows of the process and the actionable size, since any increase in the viscosities of the cylinder oil (Oil) brings about a reduction in wear (Oil).

\section{Precision of a good manufacturing process}

In addition to the defined dependence, the production process must also fulfill the requirement of suitable precision, which 


\section{Interinational Qualitity Conference}

determines the relationship between the width of the process and the prescribed limits of tolerance. The process precision (ISO 8258:1991) is defined by the process capability index PCI (Cp) according to the procedure in Figure 3. If the process is stable over time, the precision index of the pores is calculated using the following formula:

where:

$$
P C I=\frac{ \pm T}{W}
$$

$\pm T, \quad$ the width of the tolerance (between the upper and lower limits of tolerance),

$W=\sigma \cdot \hat{\sigma}$, the width of the process i $\hat{\sigma}$, the estimated standard deviation of the process.

A process that is not precise $(\mathrm{PCI}<1)$ usually has a wider process width (W) than tolerance $(\mathrm{W}> \pm \mathrm{T})$, where the process values are greater than the upper or lower than the lower limit of tolerance, so it always produces incorrect. correcting process results by changing the elements of the production or service system (eg replacing an old or worn-out machine with a new or repaired machine). The process that is critically precise $(\mathrm{PCI}=1)$ has a process width (W) which is completely equal to the tolerance $(\mathrm{W}= \pm \mathrm{T}$ ), with process value values between the upper and lower tolerance limits, so that it can give the wrong value to process the results and maintain precision process. A process that is precise (PCI> 1) usually has a smaller process width (W) than tolerance $(\mathrm{W}= \pm \mathrm{T})$, with process values that are less than the upper and higher than the lower limit of tolerance, so that it can give the correct process results without repair and changing the elements of the production or service system (Popović 2017).

If the production process is not precise, it must be improved by increasing the precision by applying the following procedures: replacement of an old or wornout machine with a new or repaired machine, replacement of the tool with a new or sharp tool, replacement of old tools or worn-out accessories for setting, tightening or guiding with new or repaired accessories, etc.

Let's look at the considered process of the investigation of the consequences of wear after rough measurements whose index of process precision is: $\mathrm{P}= \pm \mathrm{T} / \mathrm{W}=$ $200 / 6 \cdot 55,457=0,601$ and this is a poor index with respect to the precision process index (PCI> 1).

\section{Regression Analysis: Wear versus Oil}

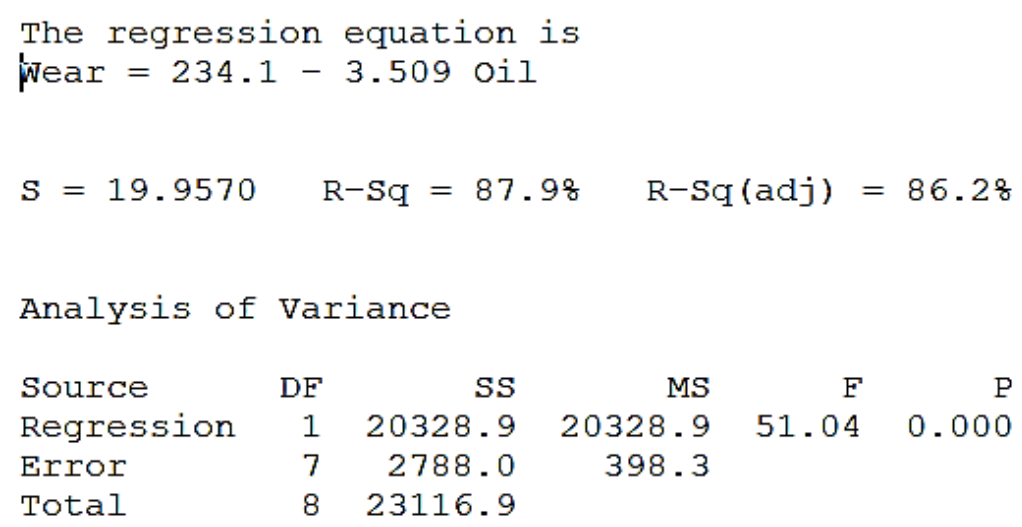

Figure 1. Tabular results of regression analysis 
Fitted Line Plot

Wear $=234.1-3.509 \mathrm{Oi}$

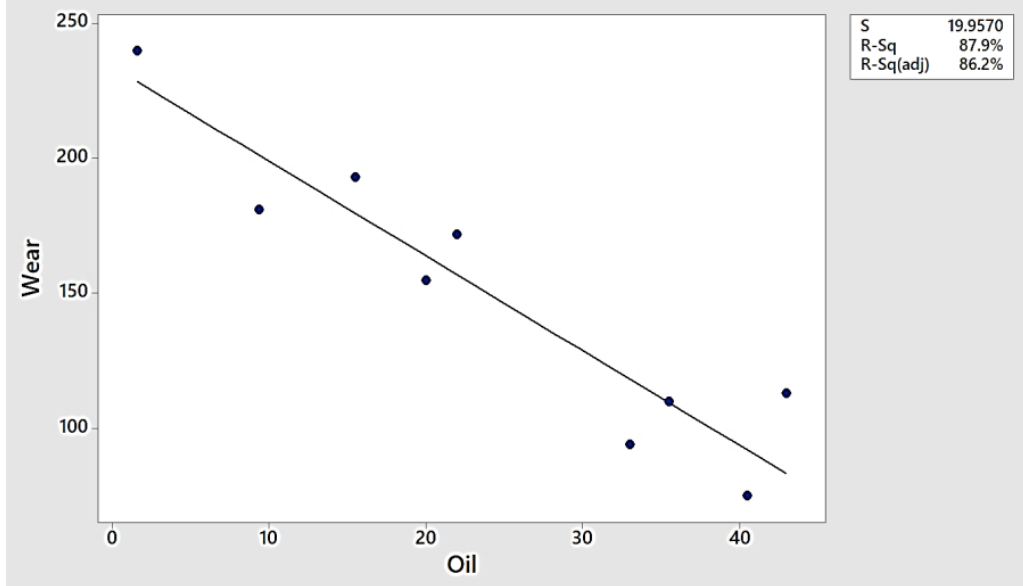

Figure 2. Regression analysis diagram

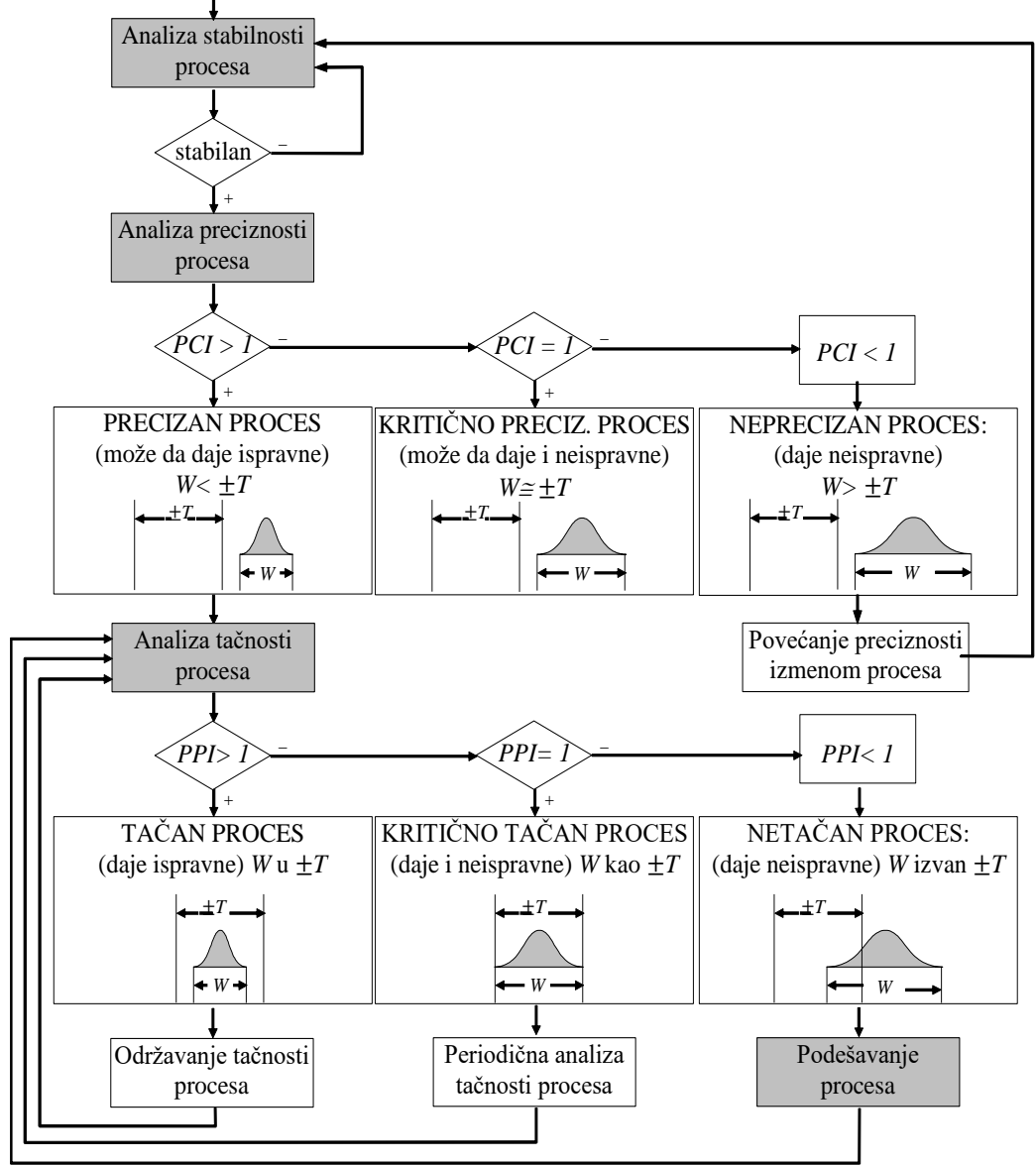

Figure 3. Analysis of the unprecision and accuracy 
The obtained result does not give a precise precision due to the rough measurement in Figure 4, so the process must be corrected by increasing the fine wear measurement with better measuring instruments. After a fine wear measurement, the following results were obtained, having an average without clustering (within) 148.3 and a standard deviation 27.4878 .

Oil: $1.6 ; 9.4 ; 15.5 ; 20.0 ; 22.0 ; 35.5 ; 43.0$; $40.5 ; 33.0[\mathrm{CP}] \mathrm{i}$

Wear: 240,$12 ; 181,20 ; 193,15 ; 155,10$; 172,$23 ; 110,14 ; 113,21 ; 75,31, \quad 94,25$ [10-4 mm3].

The process of investigating the effects of wear, which has been studied now, has a process precision index that is: $\mathrm{PCI}=$ $\pm \mathrm{T} / \mathrm{W}=200 / 6 \cdot 27,4878=1,212$, which is certainly a good index (PCI> 1$)$.

\section{The accuracy of a good manufacturing process}

In addition to the defined dependence and suitable precision, the production process must fulfill the requirement of the required accuracy of the process, which determines the position of the width of the process according to the prescribed limits of tolerance. If the process is stable over time, the index accuracy of the process (ISO 8258: 1991) is calculated using the following formula:

\section{$P P I=\min \left(P P I_{L}, P P I_{U}\right)$,}

where:

$P P I_{L}=\frac{\mu-L T L}{W}$,

$i$ index the accuracy of the the process to the lower limit of tolerance (lower), and
$P P I_{U}=\frac{U T L-\mu}{W}$,

index the accuracy of the process to the upper limit of tolerance(upper).

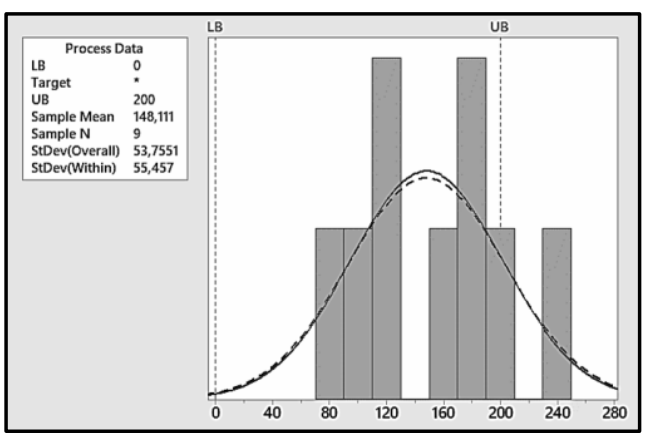

Figure 4. Unprecision process after rough measurement

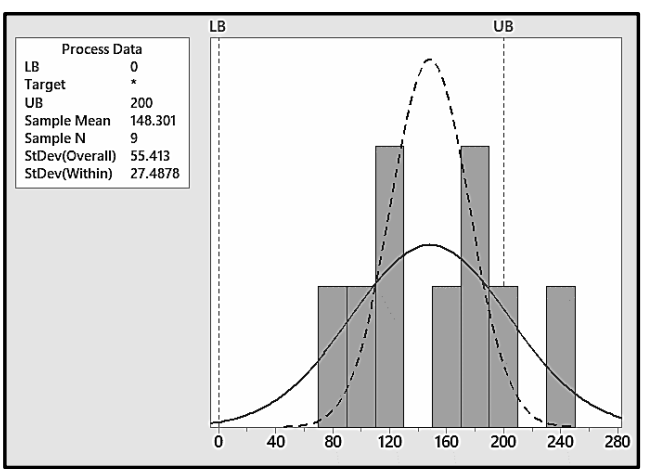

Figure 5. Precise process after fine measurements

An inaccurate process (PPI <1) usually has a process width $(\mathrm{W})$ beyond tolerance $( \pm$ $\mathrm{T}$ ), with process value values that are greater than the upper or lower than the lower limit of tolerance, so it always produces incorrect process results and needs to be adjusted (eg by moving the tool bar). The critically accurate process $(\mathrm{PPI}=1)$ has a process width $(\mathrm{W})$ within the tolerance $( \pm T)$, with process value values between upper and lower tolerance limits, so that it can give incorrect process results, so careful maintenance of accuracy process. The exact process (PPI>1) has a process width $(\mathrm{W})$ within tolerance $( \pm \mathrm{T})$, 
with process size values that are less than the upper and higher than the lower limit of tolerance, so that it gives the correct process results without setting (Popovic 2017).

If the manufacturing process is inaccurate, it must certainly be corrected by using the following procedures: setting process parameters, setting machine, tool or accessory, etc. Setting process parameters can be done using optimization: average or standard deviation, to avoid or reduce the occurrence of partial or complete malfunction of the process results. Adjusting the accuracy of the process by optimizing an average requires moving the entire width of the process $(\mathrm{W})$ relative to the tolerance $( \pm T)$, by changing the value of the tolerance limits. Setting the accuracy of the process by optimizing the standard deviation requires narrowing the width $(\mathrm{W})$ relative to the tolerance $( \pm \mathrm{T})$, by replacing the independent influencing factors.

Setting the accuracy of the considered process by optimizing the standard deviation requires the narrowing of the width $(\mathrm{W})$ relative to the tolerance $( \pm \mathrm{T})$, with a percentage reduction in the standard deviation of the factors $(-10 \%)$ and $s=$ $12,933[\mathrm{CP}]$ according to Figure 8 . The following optimization results standard deviation parameters: even higher accuracy index of the process is $\mathrm{PPI}=$ 0.7888 which is closer to the favorable index (PPI> 1) and above the tolerance limit (USL) is only $0.94 \%$ of the wear value.

\section{Sensitivity Analysis Results}

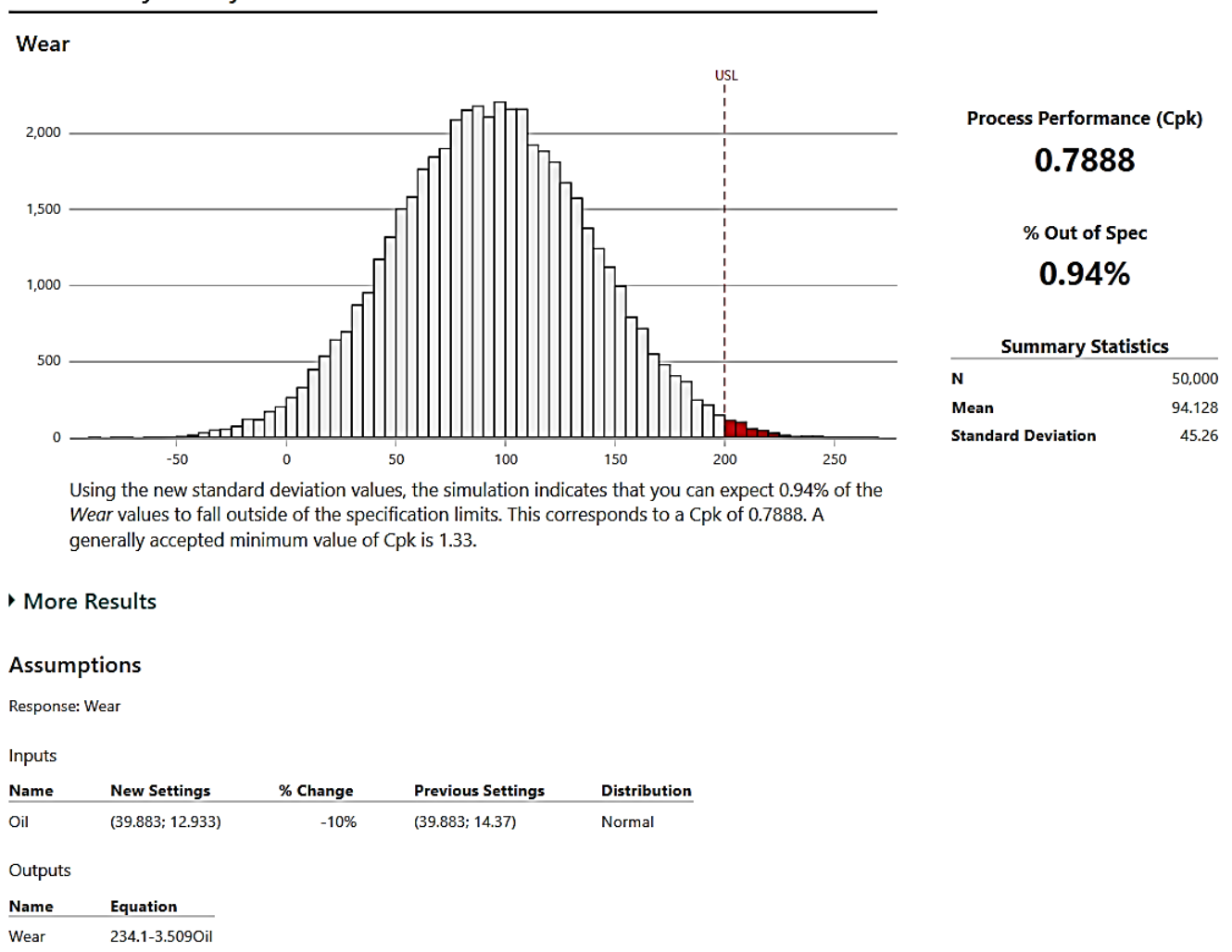

Figure 8. The obtained result of the improvement 


\section{Economics of a good manufacturing process}

In addition to the defined dependence, suitable precision and the necessary accuracy of the process, the production process must fulfill the requirements of the desirable economy, which achieves efficient reduction of excessive costs due to quality losses. The relationship between the distribution of the value of the process size and the cost of quality to Japanese engineer Dr. G. Taguchi (1924-2012) is shown in Figure 9.

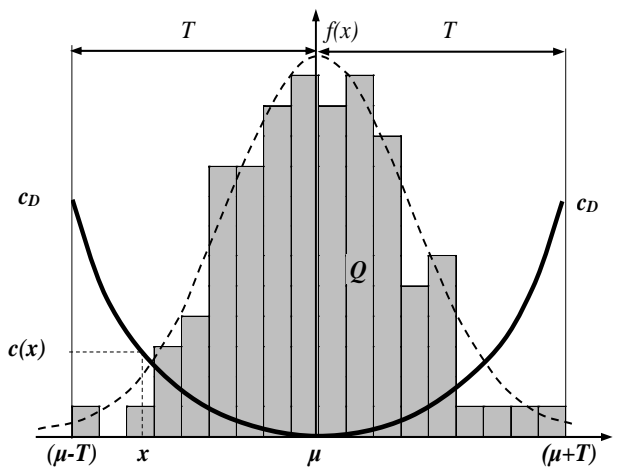

Figure 9. Diagram of the sample and the cost of quality c (x)

Values of the size (x) of the process have a convex Normal statistical distribution $\mathrm{f}(\mathrm{x})$ with average $(\mu)$ and standard deviation $(\sigma)$. The quality losses of $\mathrm{c}(\mathrm{x})$ have a concave statistical distribution within the limits of tolerance $(\mu-T, \mu+T)$ with average $(\mu)=0$, with the highest quality losses (cD) and the lowest optimal quality losses $\mathrm{c}(\mu)$ $=0$ The function of average cost of quality $\mathrm{c}(\mathrm{x})$, detection and elimination of malfunction (nonconformity, defect, correction, rework, repair and scrap) depends on the value of (x) and average $(\mu)$ :

$$
c(x)=f(x, \mu),
$$

ie if the deviation from the average is negative $(x<\mu)$ or positive $(x>\mu)$ then the costs of quality arise:

$$
c(x)=c(+\mu+x-\mu) .
$$

Obviously, this is a continuous function that has all derivatives and can be developed into the following Taylor order:

$$
c(x)=c(\mu)+\frac{c^{\prime}(\mu)}{1 !}(x-\mu)+\frac{c^{\prime \prime}(\mu)}{2 !}(x-\mu)^{2}+\ldots .
$$

Since for $(x=\mu)$ the cost of quality is equal to zero, $c(x)=0$, the first two members of the function are equal to zero, and other members of the function can be ignored, with extracts higher than the second degree:

$$
c(x)=\frac{c^{\prime \prime}(\mu)}{2 !}(x-\mu)^{2} .
$$

The value in the fraction is a certain proportional cost constant $(\mathrm{K})$, and the deviation $(x-\mu) 2$ is equal to the standard deviation $(\sigma 2)$ and is a function of the cost of quality:

$$
c(x)=K \cdot \sigma^{2} \text {. }
$$

According to the illustrated figure, if the value $(\mathrm{x})$ deviates from the average $(\mu)$ for the amount of tolerance ( $T$ ), then the average cost of quality is cD and the cost of quality according to formula (3):

$$
c_{D}=K \cdot T^{2},
$$

and as with Normal Distribution, the process has a width:

$$
2 T=6 \sigma,
$$

this formula (3) obtains the final form of the function of optimal average cost of quality (Taguchi \& Wu, 1979; Taguchi, 1978): 


$$
c(x)=\frac{c_{D}}{T^{2}} \cdot\left(\frac{2 T}{6}\right)^{2} .
$$

If the production process is uneconomical, it must definitely be corrected: by lowering the cost of quality and by reducing the malfunction of the results of the process, nonconformity, defect, correction, rework, repair and scrap of the process results.

Let us consider the investigated process of the investigation of the consequence of wear with tolerance $200\left[10^{-4} \mathrm{~mm}^{3}\right]$ and the average cost of quality $c_{D}=120 \$$ whose optimum average cost of quality is:

$$
c(x)=\frac{120}{200^{2}} \cdot\left(\frac{2 \cdot 200}{6}\right)^{2}=13,333 \$,
$$

which for $n=4$ tested tubes give optimum total cost of quality: $C(x)=n \cdot c(x)=$ $4 \cdot 13,333=53,332 \$$. This production process is not economical, so it must be improved by lowering the cost of quality, with an increase in test tubes at the same time to 8 which gives optimal total cost of quality: $C(x) / 2=53,332 / 2=4 \cdot 13,333=$ 26,666 \$.

\section{Duration of a good production process}

In addition to the defined dependency, the precise precision, the necessary process accuracy and the desirable economy, the production process must fulfill the minimum duration requirement of the process. If the production process is too long, it must definitely be corrected by shortening: preparatory and finishing times, auxiliary time and main time.

Let's look at the considered test of the impact of wear and tear, whose average duration is $720 / 4=180 \mathrm{~min} /$ pieces, which certainly needs to be corrected. With 8 simultaneously tested tubes, a shortening of the preparatory-completion time is achieved at 720/8 $=90 \mathrm{~min} /$ pieces.

\section{Conclusion}

A good manufacturing process must meet the following requirements: defined dependence, appropriate precision, necessary accuracy, desirable economy, and minimum duration. In this paper, we have demonstrated ways that the poor production process can be repaired so that it becomes a good process, using the modern Minitab ${ }^{\circledR}$ and Companion by Minitab® computer programs.

If the manufacturing process is unprecision, it can be corrected by increasing the precision, e.g. replacing an old or worn-out machine with a new or repaired machine, if the manufacturing process is inaccurate, it can be corrected by applying the process parameters setting, e.g. by optimizing the average or standard deviation, the production process is uneconomical, it can be corrected, for example, by lowering the optimum average cost of quality and, finally, if the process is too long, it can be corrected by shortening, e.g. preparation and finishing times. 


\section{References:}

Popović B., Optimalno rešavanje problema - Optimal Solving of Problems, Akademska misao, Beograd (2019) 265,

Popović B., Optimalni troškovi kvaliteta - Optimall costs of quality, Akademska misao, Beograd (2018) 170,

Popović B., Simulacija poslovnih procesa - Simulatio of Business Procesess, Akademska misao, Beograd (2017) 359,

Popović B., Sistem šest sigma u u povišenju profita - System Six sigma, Akademska misao, Beograd (2016) 187

Popović B, Kako izbeći kontrolisanje svakog proizvoda, Kvalitet \& Izvrsnost 7-8 (2017) 78-80

Popović B, Kako kontrolisati kvalitet tačnih i netačnih procesa, Kvalitet \& Izvrsnost, Beograd (2017) 5-6

Popović B, Kontrolisanje proizvoda, procesa ili troškova? Kvalitet \& Izvrsnost, Beograd (2015) 7-8, 40-43

Popović B., Klarin M., Upravljanje proizvodnjom i usluživanjem - Operations Management, Mašinski fakultet, Beograd (2005) 599

Popović B., Klarin M., Upravljanje proizvodnjom i usluživanjem - Operations Management, Mašinski fakultet, Beograd (2005) 599

Taguchi; G., Chowdhury, S.,; Wu, Y., Taguchi's Quality Engineering Handbook. John Wiley (2005)

Taguchi, G. (1981). On-line quality control during production. Japan Standards Association.

Taguchi, G., \& Wu, Y. (1979). Introduction to off-line quality control. Central Japan Quality Control Assoc..

Taguchi, G. (1978, October). Off-line and on-line quality control systems. In Proceedings of International Conference on Quality Control.

\section{Branko Z. Popović}

Mašinski fakultet

Univerziteta u Beogradu,

Beograd,

Serbia

branko@popovic.org 
13.110C International Cuality Conference 